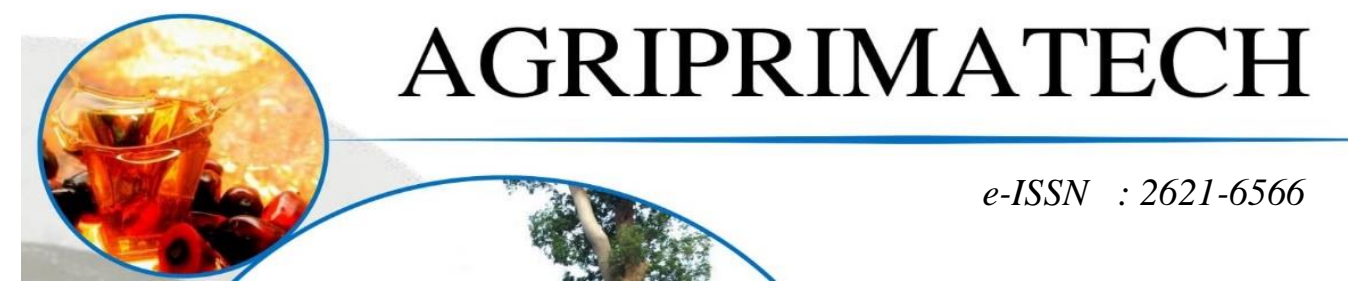

\title{
DAMPAK BERDIRINYA PERUSAHAAN KELAPA SAWIT TERHADAP KONDISI SOSIAL EKONOMI MASYARAKAT SEKITAR
}

\author{
IRA APRIYANTI ${ }^{1}$, ABEDNEGO SURANTA KAROSEKALI², MUHAMMAD ASYIYAMI \\ MUNTHAHA ${ }^{3}$ \\ ${ }^{1}$ Fakultas Pertanian, Universitas Muhammadiyah Sumatera Utara \\ ${ }^{2,3}$ Fakultas Agro Teknologi, Universitas Prima Indonesia
}

Email: iraapriyanti@gmail.com

\begin{abstract}
ABSTRAK
Perubahan yang terjadi akibat berdirinya perusahaan kelapa sawit akan menimbulkan dampak positif atau sebaliknya akan menimbulkan hal-hal negatif yang justru merugikan masyarakat sekitar. Hal ini yang melatar belakangi penelitian karena penulis ingin mengetahui bagaimana dampak keberadaan perusahaan terhadap kondisi sosial dan ekonomi masyarakat sekitar. Penelitian ini bertujuan untuk melihat dampak yang ditimbulkan oleh keberadaan perusahaan terhadap kondisi sosial dan ekonomi masyarakat yang tinggal di lokasi sekitar perusahaan. Penelitian ini menyimpulkan bahwa dampak keberadaan perusahaan kelapa sawit di Desa Blankahan secara sosial dan ekonomi membawa banyak dampak positif. Adapun dampak positif terhadap kondisi sosial terlihat pada Pembangunan Fasilitas Umum, Pendidikan, Kesehatan dan Terhadap Pranata Sosial Lembaga- Lembaga masyarakat. Dampak positif terhadap kondisi ekonomi terlihat pada Kesempatan bekerja/berusaha semakin terbuka dengan adanya PT. United Kingdom Indonesia Plantations, sehingga dapat membantu pemerintah dalam mengurangi angka pengangguran di Desa Blankahan.
\end{abstract}

Kata Kunci: Dampak, Perusahaan, Kelapa Sawit, Sosial, Ekonomi.

\section{PENDAHULUAN}

Sumbangan sektor pertanian selalu menduduki posisi yang sangat vital, pada negara berkembang seperti Indonesia sehingga sektor pertanian diletakkan sebagai andalan pembangunan nasional yang didukung oleh unsur-unsur kekuatan yang dimiliki. Pembangunan senantiasa berkembang sejalan dengan perkembangan masyarakat dan ilmu pengetahuan, pembangunan pertanian memiliki arti penting untuk meningkatkan pertumbuhan ekonomi nasional sekaligus meningkatkan taraf hidup petani. Perubahan yang dibawa pembangunan hendaknya di rencanakan dan disesuaikan dengan kehendak rakyat. Pembangunan seharusnya memenuhi kehendak masyarakat yang terwujud dalam keputusan dan kebijakan yang diambil oleh pemerintah. Rusmawardi (2007) mengemukakan bahwa pembangunan di sektor pertanian pada tahapan tertentu akan membuat peluang pengembangan agribisnis yang

cukup besar, karena bertumpuh diatas landasan keunggulan komparatif dalam memproduksi berbagai bahan mentah berupa komoditas perkebunan, holtikultura, peternakan dan perikanan serta peluang pasar 
Vol. 3 No. 2, April 2020

baik didalam maupun luar negeri. Peluang-peluang agribisnis yang tercipta akan menimbulkan stimulan terhadap investasi di bidang agribisnis, yang ditandai dengan berdirinya perusahaan- perusahaan yang bergerak di bidang perkebunan kelapa sawit. Berdirinya perusahaanperusahaan di suatu daerah tertentu seharusnya berpengaruh terhadap kondisi perekonomian nasional serta memiliki dampak terhadap kondisi sosial ekonomi masyarakat di sekitar perusahaan-perusahaan itu didirikan.

\section{METODE PENELITIAN}

Penelitian ini akan dilaksanakan di PT. United Kingdom Indonesia Plantations, Desa Blankahan, Kecamatan Kuala, Kabupaten Langkat, Provinsi Sumatera Utara, mulai bulan Februari tahun 2016 sampai dengan bulan Maret tahun 2016. Dalam penelitian ini di gunakan metode analisis deskriptif dan induktif. Metode penelitian deskriptif dimana dalam pelaksanaannya meliputi data, analisis dan interpretasi tentang arti dan data yang diperoleh. Penelitian ini disusun sebagai penelitian induktif yakni mencari dan mengumpulkan data yang ada di lapangan dengan tujuan untuk mengetahui faktor-faktor, unsur-unsur bentuk, dan suatu sifat dari fenomena di masyarakat.

\section{Metode Pengumpulan Data}

Penelitian ini dilakukan dengan mengambil data primer dan data sekunder.

1. Data primer adalah data yang diambil dari sumber data primer atau sumber pertama dilapangan. Sumber data ini adalah sumber

\author{
e-ISSN : 2621-6566 \\ pertama dimana sebuah data \\ dihasilkan.
}

2. Data sekunder adalah data yang diperoleh dari sumber kedua atau sumber sekunder. Sumber data sekunder dapat membantu memberi keterangan, atau data pelengkap sebagai bahan pembanding. Data sekunder ini biasa berbentuk data yang tersaji dalam bentuk tabel, grafik, internet dan lain sebagainya. Sumber data sekunder dapat berasal dari peneliti sebelumnya, lembaga pemerintah, lembaga swasta, dan lain sebagainya. Untuk memperoleh data yang akurat maka teknik pengumpulan data dalam penelitian ini dilakukan langsung pada objek sasaran yaitu dengan menggunakan teknik sebagai berikut:

(1) Metode angket atau kuesioner

(2) Metode wawancara

(3) Metode observasi atau pengamatan

\section{Analisis Data}

Penelitian ini menggunakan analisis deskriptif untuk mengetahui dampak berdirinya perusahaan kelapa sawit (Eliaeis guineensis jacq) PT. United Kingdom Indonesia Plantation Terhadap Kondisi Sosial Ekonomi Masyarakat Di Desa Blankahan, Kecamatan Kuala, Kabupaten Langkat, Provinsi Sumatera Utara.

\section{Uji Hipotesis t-Statistik}

Uji t-statistik diperlukan untuk menguji hipotesis penelitian. Pengujian dilakukan dengan cara berpasangan. Perhitungan uji t-statistik berpasangan dilakukan dengan software SPSS. 
HASIL PENELITIAN DAN PEMBAHASAN

Rekapitulasi Jawaban Responden dilihat dari Indikator Sosial

\begin{tabular}{|c|c|c|c|c|c|c|c|}
\hline \multirow{2}{*}{ No } & \multirow{2}{*}{$\begin{array}{l}\text { Indikator Dan } \\
\text { Pertanyaan }\end{array}$} & \multicolumn{5}{|c|}{ Frekuensi/Persentase } & \multirow{2}{*}{$\begin{array}{l}\text { Jumlah } \\
\text { Respon- } \\
\text { Den }\end{array}$} \\
\hline & & $\begin{array}{l}\text { Sangat } \\
\text { Baik (5) }\end{array}$ & $\begin{array}{l}\text { Baik } \\
(4)\end{array}$ & $\begin{array}{l}\text { Kurang } \\
\text { Baik (3) }\end{array}$ & $\begin{array}{l}\text { Tidak } \\
\text { Baik (2) }\end{array}$ & $\begin{array}{l}\text { Sangat } \\
\text { Tidak } \\
\text { Baik } \\
(1)\end{array}$ & \\
\hline 1 & $\begin{array}{l}\text { 1. Kesehatan } \\
\text { a. Sarana } \\
\text { Kesehatan }\end{array}$ & - & $\begin{array}{l}21 \\
(70)\end{array}$ & $\begin{array}{c}9 \\
(30)\end{array}$ & - & - & $\begin{array}{c}30 \\
(100)\end{array}$ \\
\hline 2 & $\begin{array}{l}\text { b. Keahlian Tenaga } \\
\text { Kesehatan }\end{array}$ & - & - & $\begin{array}{c}8 \\
(26,7)\end{array}$ & $\begin{array}{l}21 \\
(70)\end{array}$ & $\begin{array}{c}1 \\
(3,3)\end{array}$ & $\begin{array}{c}30 \\
(100)\end{array}$ \\
\hline 3 & $\begin{array}{l}\text { c. Penyuluhan } \\
\text { Dan Program } \\
\text { Kesehatan }\end{array}$ & $\begin{array}{c}1 \\
(3,3)\end{array}$ & $\begin{array}{c}17 \\
(56,7)\end{array}$ & $\begin{array}{c}12 \\
(40)\end{array}$ & - & - & $\begin{array}{c}30 \\
(100)\end{array}$ \\
\hline 4 & $\begin{array}{l}\text { 2. Pendidikan } \\
\text { a. Angka } \\
\text { Partisipasi } \\
\text { Bersekolah }\end{array}$ & $\begin{array}{c}1 \\
(3,3)\end{array}$ & $\begin{array}{l}21 \\
(70)\end{array}$ & $\begin{array}{c}8 \\
(26,7)\end{array}$ & - & - & $\begin{array}{c}30 \\
(100)\end{array}$ \\
\hline 5 & $\begin{array}{l}\text { b. Fasilitas } \\
\text { Pendidikan }\end{array}$ & $\begin{array}{c}2 \\
(6,7)\end{array}$ & $\begin{array}{c}16 \\
(53,3)\end{array}$ & $\begin{array}{c}12 \\
(40)\end{array}$ & - & - & $\begin{array}{c}30 \\
(100)\end{array}$ \\
\hline 6 & $\begin{array}{l}\text { c. Keahlian } \\
\text { Tenaga Pengajar }\end{array}$ & $\begin{array}{c}2 \\
(6,7)\end{array}$ & $\begin{array}{c}25 \\
(83,3)\end{array}$ & $\begin{array}{c}3 \\
(10)\end{array}$ & - & - & $\begin{array}{c}30 \\
(100)\end{array}$ \\
\hline 7 & $\begin{array}{l}\text { 3. Fasilitas } \\
\text { Prasarana } \\
\text { a. Prasarana } \\
\text { Jalan/Akses Desa }\end{array}$ & & $\begin{array}{c}11 \\
(36,7)\end{array}$ & $\begin{array}{c}19 \\
(63,3)\end{array}$ & - & - & $\begin{array}{c}30 \\
(100)\end{array}$ \\
\hline
\end{tabular}




\begin{tabular}{|c|c|c|c|c|c|c|c|}
\hline 8 & $\begin{array}{l}\text { 4. Fasilitas } \\
\text { Prasarana } \\
\text { dan kesehatan } \\
\text { a. Jumlah Sekolah }\end{array}$ & & $\begin{array}{c}1 \\
(3,3)\end{array}$ & $\begin{array}{c}3 \\
(10)\end{array}$ & $\begin{array}{l}24 \\
(80)\end{array}$ & $\begin{array}{c}2 \\
(6,7)\end{array}$ & $\begin{array}{c}30 \\
(100)\end{array}$ \\
\hline 9 & $\begin{array}{l}\text { b. Jumlah } \\
\text { Klinik/Puskesmas }\end{array}$ & & - & $\begin{array}{c}3 \\
(10)\end{array}$ & $\begin{array}{c}20 \\
(66,7)\end{array}$ & $\begin{array}{c}7 \\
(23,3)\end{array}$ & $\begin{array}{c}30 \\
(100)\end{array}$ \\
\hline & Jumlah & $\begin{array}{c}6 \\
(2,2)\end{array}$ & $\begin{array}{l}112 \\
(41,5)\end{array}$ & $\begin{array}{c}77 \\
(28,5)\end{array}$ & $\begin{array}{c}65 \\
(24,1)\end{array}$ & $\begin{array}{c}10 \\
(3,7)\end{array}$ & $\begin{array}{l}270 \\
(100)\end{array}$ \\
\hline
\end{tabular}

\section{Hasil Rekapitulasi Jawaban Responden Indikator Sosial}

Dari uraian hasil rekapitulasi jawaban pernyataan responden mengenai dampak sosial dapat dikategorikan Maksimal. Hal ini dapat dilihat bahwa sebanyak 112 (41,5\%) responden yang menjawab baik hal didukung oleh hasil angket dan observasi yang penulis lakukan, yang menunjukan :

1. Dampak Berdirinya PT. United Kingdom Indonesia Plantations sangat Berdampak pada Pembangunan Fasilitas Umum, Pendidikan, Kesehatan dan Terhadap Pranata Sosial LembagaLembaga masyarakat.

2. Masyarakat setempat selalu dilibatkan oleh PT. United Kingdom Indonesia Plantations dalam proses kegiatan sosial/kerjasama untuk kepentingan masyarakat Desa Blankahan

3. Adanya alkulturasi (pembauran), asimilasi dan integrasi (penyesuaian) yang diterapkan oleh
PT. United Kingdom Indonesia Plantations berpengaruh baik terhadap kehidupan masyarakat setempat.

4. Dampak Berdirinya PT. United Kingdom Indonesia Plantations terhadap kehidupan sosial masyarakat dapat dilihat melalui peningkatan kualitas pendidikan, kesehatan, tempat tinggal, sarana dan prasarana umum dan perkembangan daerah di Desa Blankahan yang sudah menjadi sejahtera.

5. Dampak Berdirinya PT. United Kingdom Indonesia Plantations dapat merubah pandangan masyarakat terhadap lingkungan, perubahan kepemilikan sumber daya alam dan pola bercocok tanam.

6. Kegiatan sosial yang dibuat oleh PT. United Kingdom Indonesia Plantations mendapat respon positif dari masyarakat. 
Rekapitulasi Jawaban Responden dilihat dari Indikator Ekonomi

\begin{tabular}{|c|c|c|c|c|c|c|c|}
\hline \multirow[b]{2}{*}{ No } & \multirow{2}{*}{$\begin{array}{l}\text { Indikator Dan } \\
\text { Pertanyaan }\end{array}$} & \multicolumn{5}{|c|}{ Frekuensi/Persentase } & \multirow{2}{*}{$\begin{array}{l}\text { Jumlah } \\
\text { Respon- } \\
\text { Den }\end{array}$} \\
\hline & & $\begin{array}{l}\text { Sangat } \\
\text { Baik }\end{array}$ & Baik & $\begin{array}{l}\text { Kurang } \\
\text { Baik }\end{array}$ & $\begin{array}{l}\text { Tidak } \\
\text { Baik }\end{array}$ & $\begin{array}{l}\text { Sangat } \\
\text { Tidak } \\
\text { Baik }\end{array}$ & \\
\hline 1 & $\begin{array}{l}\text { 1. Pendapatan/ } \\
\text { Kapita } \\
\text { a. Tingkat } \\
\text { Pengeluaran }\end{array}$ & - & $\begin{array}{c}7 \\
(23,3)\end{array}$ & $\begin{array}{c}20 \\
(66,7)\end{array}$ & $\begin{array}{r}3 \\
(10)\end{array}$ & - & $\begin{array}{c}30 \\
(100)\end{array}$ \\
\hline 2 & $\begin{array}{l}\text { b. Ketersediaan } \\
\text { Lapangan Kerja }\end{array}$ & $\begin{array}{c}1 \\
(3,3)\end{array}$ & $\begin{array}{c}16 \\
(53,3)\end{array}$ & $\begin{array}{c}13 \\
(43,3)\end{array}$ & - & - & $\begin{array}{c}30 \\
(100)\end{array}$ \\
\hline 3 & $\begin{array}{l}\text { c. Tingkat } \\
\text { Partisipasi } \\
\text { Angkatan Kerja }\end{array}$ & - & $\begin{array}{l}18 \\
(60)\end{array}$ & $\begin{array}{c}11 \\
(36,7)\end{array}$ & $\begin{array}{c}1 \\
(3,3)\end{array}$ & - & $\begin{array}{c}30 \\
(100)\end{array}$ \\
\hline 4 & $\begin{array}{l}\text { 2. Tingkat } \\
\text { Pendapatan } \\
\text { a. Pendapatan } \\
\text { Perbulan }\end{array}$ & - & $\begin{array}{r}3 \\
(10)\end{array}$ & $\begin{array}{r}3 \\
(10)\end{array}$ & $\begin{array}{c}16 \\
(53,3)\end{array}$ & $\begin{array}{c}8 \\
(26,7)\end{array}$ & $\begin{array}{c}30 \\
(100)\end{array}$ \\
\hline & Jumlah & $\begin{array}{c}1 \\
(0,8)\end{array}$ & $\begin{array}{c}44 \\
(36,7)\end{array}$ & $\begin{array}{c}47 \\
(39,1)\end{array}$ & $\begin{array}{c}20 \\
(16,7)\end{array}$ & $\begin{array}{c}8 \\
(6,7)\end{array}$ & $\begin{array}{l}120 \\
(100)\end{array}$ \\
\hline
\end{tabular}

Hasil Rekapitulasi Jawaban Responden Indikator Ekonomi

Dari uraian hasil rekapitulasi jawaban pernyataan responden mengenai indikator ekonomi dapat dikategorikan kurang maksimal. Hal ini dapat dilihat bahwa hanya sebanyak $47(39,1 \%)$ responden yang menjawab kurang baik hal didukung oleh hasil angket dan observasi yang penulis lakukan, yang menunjukan:

1. Kesempatan bekerja/berusaha semakin terbuka dengan adanya PT. United Kingdom Indonesia 
Vol. 3 No. 2, April 2020

Plantations, sehingga dapat meminimalisir (mengurangi) angka pengangguran di Desa Blankahan.

2. PT. United Kingdom Indonesia Plantations lebih mengutamakan masyarakat setempat (pribumi) dalam memberikan kesempatan bekerja/berusaha.

3. Pendapatan masyarakat meningkat dengan adanya PT. United Kingdom Indonesia Plantations sehingga perekonomian masyarakat menjadi sejahtera.

4. Sarana dan prasarana infrastruktur berupa jalan umum, fasilitas pendidikan, rumah ibadah, rumah sakit dan fasilitas umum lainnya semakin baik dan tersedia dengan keberadaan PT. United Kingdom Indonesia Plantations.

5. Masyarakat lebih mngetahui pola pemanfaatan sumber daya alam yang ada setelah adanya PT. United Kingdom Indonesia Plantations dengan mengalihkan fungsi lahan menjadi kebun sawit.

\section{KESIMPULAN}

1. Ada dampak sosial masyarakat Desa Blankahan setelah berdirinya PT. United Kingdom Indonesia Plantations meliputi perubahan perubahan terhadap pentingnya pendidikan dan kesehatan, perubahan struktur sosial yang telihat dari perubahan status sosial masyarakat Desa Blankahan dan bertambahnya jumlah penduduk yang menyebabkan mobilitas masyarakat meningkat.

2. Ada dampak ekonomi masyarakat setelah berdirinya PT. United Kingdom Indonesia Plantations adalah terbukanya lapangan perkerjaan baru di PT. United Kingdom Indonesia Plantations dan munculnya pekerjaan sampingan disektor informal seperti membuka rumah makan, membuka bengkel, tempat mencucian mobil dan sebagainya. Adanya lapangan pekerjaan baru dan pekerjaan

$\begin{array}{lr}\text { disektor informal } & \begin{array}{r}\text { membuat } \\ \text { mertambahnya }\end{array} \\ \text { masyarakat. } & \text { penghasilan }\end{array}$

\section{DAFTAR PUSTAKA}

Abraham, V.L. 2013. Pengakuan Pendapatan Dan Beban Atas Laporan Keuangan Pada PT. Bank Sulut. Jurnal Ekonomi Manajemen Bisnis dan Akutansi (EMBA), Vol.1 No.3, Juni $2013 \quad$ Hal.201. http://id.portalgaruda.

org/?ref=browse\&mod=viewarti cle\&article $=108779$.

Badan Pusat Statistik. Provinsi Sumatera Utara 2015. Langkat Dalam Angka 2015. Langkat : Badan Pusat Statistik.

Badan Pusat Statistik. 2009. Indikator Kesejahteraan. www.bps.go.id. diakses pada tanggal 12 maret 2016.

Bungin, M.B. 2013. Metodologi Sosial dan Ekonomi. Jakarta. Kencana Prenada Media Group.

\author{
Haryanto. 2012. Pengertian \\ Perubahan Sosial. \\ http://belajarpsikologi.com/ \\ bentuk-bentuk-p.
}

Haryanto. 2012. Bentuk-Bentuk Perubahan Sosial Masyarakat. http://belajarpsikologi.com/pengertian-perubahansosial. Diunduh pada tanggal 11 November 2015.

Herimanto dan Winarno. 2008. IImu Sosial dan Budaya Dasar. Jakarta. Bumi Aksara.

Imbiri, Soleman. 2010. Analisis Dampak PIR Kelapa Sawit Terhadap Kesejahteraan Masyarakat erubahan-sosialmasyarakat. Diunduh pada tanggal 11 November 2015.

Ishomuddin. 1992. Pengantar 
Agriprimatech

Vol. 3 No. 2, April 2020

Sosiologi Agama. Jakarta: Ghalia Indonesia. Nirtasari. 2013. Perubahan Sosial Ekonomi Masyarakat Desa Tanah Abang

Kecamatan Batang Hari Leko Kabupaten Musi Banyuasin Setelah Berdirinya PT. Perkebunan Mitra Ogan. http://www.akademik.unsri.ac.id /paper3 /download /paper/TA07091002045.pdf. Diunduh pada tanggal 1 Oktober 2015.

Nurmanaf. 1988. Struktur Pendapatan Rumah Tangga Petani Sawah di Pedesaan Jawa Barat Prosiding Perubahan Ekonomi Pedesaan menuju Ekonomi Berimbang. Bogor: Pusat Penelitian Agro Ekonomi.

Ridar, Juan. 2014. Analisis Dampak Keberadaan PKS PT. Perkebunan Nusantara $V$ Tandun Terhadap Sosial Ekonomi Masyarakat Di Kecamatan Tandun Kabupaten Rokan Hulu. http://repository.uinsuska.ac.id/886/6/BAB\% 20V.pdf. Diunduh pada tanggal 1 Oktober 2015.

Rusmawardi. 2007. Dampak Berdirinya Perkebunan Kelapa Sawit (Elaeis guineensis jack) Terhadap Kondisi Sosial Ekonomi Masyarakat (Studi Kasus Pada desa Kabuau, Kecamatan Parenggean, Kabupaten Kota waringin Timur, Propinsi Kalimantan Tengah). http://core.ac.uk/ download/pdf/12145950.pdf.

Diunduh pada tanggal 15 agustus 2015 .

Samsu, Saharia. 2013. Analisis Pengakuan Dan Pengukuran

$$
\text { e-ISSN : 2621-6566 }
$$

Pendapatan Berdasarkan

PSAK No 23 Pada PT. Misa

Utara Manado. Jurnal

Ekonomi

Manajemen Bisnis dan Akutansi (EMBA), Vol.1 No.3, Juni 2013 Hal.568-569.

http://id.portalgaruda.org/index.p hp?ref=browse\&mod=viewarticl e\& article $=108831$. Diunduh pada tanggal 11 November 2015.

Suriati, Afrina. 2013. Kondisi Sosial Ekonomi Masyarakat Sebelum Dan Sesudah Berdirinya PT. Bina Pratama Sakato jaya Solok Selatan 1 (PT. BPSJSS1) Di Kanagarian Abai Kecamatan Sangir Batang Hari Kabupaten Solok Selatan. http://ejournal-s1.stkip-pgrisumbar.ac.id/index.php/geogr afi/ search/results. Diunduh pada tanggal 10 September 2015.

Soedharto. 2000. Kapita Selekta Hukum Pidana. Bandung: Citra Aditya Bakti. Soeharjo, A. 1973. Sendi-Sendi Pokok IImu Usahatani. Bogor: Departemen IImu SosialEkonomi Fakultas pertanian.

Soemartono, Gatot P. 2011. Hukum Lingkungan Indonesia. Jakarta: Sinar Grafika. Syamsuddin. 2011. Dampak Berdirinya Perusahaan Kelapa Sawit (PT. Damai Jaya Lestari) Terhadap Kondisi Sosial Ekonomi Masyarakat di Desa Tondowolio. Skripsi. Universitas Muhammadiyah Malang. Fakultas Pertanian. ediusman92.blogspot.com/201 4/03/proposal-penelitiandampak berdirinya.html diakses pada tanggal 11 November 2015. 